BMJ Open

Diabetes

Research

\& Care

\title{
Adolescents' perceptions of participation in group education using the Guided Self-Determination-Young method: a qualitative study
}

\author{
Anna Lena Brorsson, ${ }^{1,2}$ Anna Lindholm Olinder, ${ }^{3,4}$ Gunnel Viklund, \\ Therese Granström, ${ }^{2,3}$ Janeth Leksell ${ }^{2,3}$
}

To cite: Brorsson AL, Lindholm Olinder A, Viklund G, et al. Adolescents' perceptions of participation in group education using the Guided Self-Determination-Young method: a qualitative study. BMJ Open Diab Res Care 2017;5:e000432. doi:10.1136/ bmjdrc-2017-000432

Received 20 April 2017 Revised 30 October 2017 Accepted 9 November 2017

\section{CrossMark}

'Department of Women's and Children's Health, Karolinska Institutet and Karolinska University Hospital, Stockholm, Sweden

${ }^{2}$ School of Education, Health and Social Studies, Högskolan Dalarna, Falun, Sweden ${ }^{3}$ Department of Medical Sciences, Uppsala University, Uppsala, Sweden

${ }^{4}$ Department of Clinical Science and Education, Karolinska Institute, Stockholm, Sweden

Correspondence to Dr Anna Lena Brorsson; anna-lena.brorsson@ki.se

\section{ABSTRACT}

Objective Guided Self-Determination (GSD) is a personcentered communication and reflection method. Education in groups may have a greater impact than the content of the education, and constructive communication between parents and adolescents has been shown to be of importance. The purpose of this study was to describe adolescents' perceptions of participation in group education with the Guided Self-Determination-Young (GSD-Y) method, together with parents, in connection with the introduction of continuous subcutaneous insulin infusion.

Research design and methods In the present qualitative interview study, 13 adolescents with type 1 diabetes were included after completing a GSD-Y group education program in connection with the introduction of continuous subcutaneous insulin infusion at three hospitals located in central Sweden. The adolescents were interviewed individually, and qualitative content analysis was applied to the interview transcripts.

Results Two categories that emerged from the analysis were the importance of context and growing in power through the group process. An overarching theme that emerged from the interviews was the importance of expert and referent power in growing awareness of the importance of self-management as well as mitigating the Ioneliness of diabetes.

Conclusions GSD-Y has, in various ways, mitigated experiences of loneliness and contributed to conscious reflection about self-management in the group (referent power) together with the group leader (expert power). Overall, this highlights the benefits of group education, and the GSD method emphasizes the person-centered approach.

Trial registration number ISRCTN22444034; Results

\section{INTRODUCTION}

Adolescence, the period of transition to independence, comprises major changes in cognitive and emotional maturity, when an identity separate from one's family has to be created. ${ }^{1}$ During this period, a transparent responsibility distribution is necessary between adolescent and parents for diabetes-related issues, to achieve a level of diabetes self-management

\section{Significance of this study}

What is already known about this subject?

- Adolescents participating individually in an intervention with Guided Self-Determination-Young experience growth in life skills, which to them involves new relationships with health professionals and parents, and personal maturity.

- Constructive communication between parents and adolescents has been shown to be an important component of self-management.

What are the new findings?

- For adolescents with diabetes, it is important to be able to meet other young people in the same situation and to share experiences of living with diabetes. This creates a sense of belonging and of not being alone in having diabetes.

- Parental participation is important in group education with adolescents with type 1 diabetes.

How might these results change the focus of research or clinical practice?

- These findings highlight how structured diabetesrelated conversations using Guided SelfDetermination-Young in groups inspired young people and created ideas for how to deal with and solve diabetes-related issues.

- Further studies are needed to investigate factors contributing to loneliness in adolescents living with diabetes and explore whether young people with type 1 diabetes feel more lonely than young people without diabetes.

that works in everyday life. ${ }^{2}$ At the same time, the responsibility for diabetes management should be transferred from the parents to the adolescent. ${ }^{3}$ Factors that seem to facilitate diabetes self-management during this period are cognitive maturity, personal qualities, experience, social network, and parental involvement. ${ }^{4} \mathrm{WHO}$ defines adolescents as those aged between 10 and 19 years. ${ }^{5}$ Scholes et $a t^{6}$ reported that adolescents receiving 
parental support have a less negative perception of the disease and better glycemic control, and are more active in their diabetes self-management.

It is a challenge to find suitable interventions that support adolescents with diabetes and their parents during this period. The International Society for Pediatric and Adolescent Diabetes suggested that diabetes care has to be adaptable and person-centered tailored to each individual's age, maturity, and lifestyle. ${ }^{7}$

In the meeting between health professionals and people with diabetes, Zoffmann and Kirkevold ${ }^{8}$ have shown that there are barriers within and between patient and healthcare personnel, and that those involved have difficulty getting past these barriers. Based on this, a person-centered communication and reflection method called Guided Self-Determination (GSD) was developed, in which shared decision-making in chronic care means that health professionals gain insight into the patient's decisions and not vice versa. The method shows that the choices of communication and reflection form are crucial to whether or not shared decision-making is achieved. ${ }^{9}$ After participating in sessions using Guided Self-Determination-Young (GSD-Y, a GSD method adapted for adolescents and parents), adolescents demonstrated development in life skills. ${ }^{10}$ In an ongoing randomized controlled trial (RCT), ${ }^{11}$ the GSD-Y method is evaluated in connection with the introduction of continuous subcutaneous insulin infusion (CSII). The intervention group attended a GSD-Y education program consisting of seven sessions (about 2 hours per session). The first three were held in connection with the introduction of insulin pump use and were followed by four sessions, one each month. Before each session, the participants completed specific reflection worksheets (table 1). The group leaders used different communication models to prompt conversations (mirroring, active listening, and value-clarifying responses). Brorsson $e t a l^{11}$ described the RCT in more detail in a study protocol.

There is a lack of qualitative studies evaluating group education interventions on adolescents with type 1 diabetes, ${ }^{12} 13$ and the present study contributes to filling this knowledge gap. The purpose of this study was to qualitatively describe adolescents' perceptions of participation in group education with the GSD-Y method, together with parents, in connection with the introduction of CSII.

\section{RESEARCH DESIGN AND METHODS}

This is a qualitative interview study evaluating a GSD-Y intervention in connection with the introduction of CSII. Qualitative content analysis, inspired by Krippendorff ${ }^{14}$ has been used in the inductive analyses.

\section{Participants and settings}

Purposeful sampling was used with maximum variation. ${ }^{15}$ Purposeful sampling is widely used in qualitative research for the identification and selection of information-rich cases related to the phenomenon of interest, and Kvale and Brinkmann ${ }^{16}$ recommend $15 \pm 10$ interviews. We
Table 1 Overview of content in the GSD-Y sessions

Session 1 Your life with diabetes from the beginning to (start CSII) now

- Written invitation to work together in a new way

- Two ways of looking at $\mathrm{HbA1c}$

- Agreement on things to work on

Session 2 Your life with diabetes from the beginning to (start CSII) now

- Important events and periods in your life

-What do you find difficult at present living with your diabetes?

- Your plans for changing your way of life

Session 3 Values and opportunities

(start CSII) - Unfinished sentences: needs, values, experiences, and opportunities (parents)

Session 4 Diabetes in your life

- A picture or expression describing your life with diabetes

- Room for diabetes in your life (parents)

- Shared responsibility between adolescent and parent for diabetes in daily life

- Common name for a difficulty in your life with diabetes

- Agreement on things to work on until next visit

Session 5 Problem identification and problem-solving

- Current problem-solving (parents)

- Dynamic problem-solving (parents)

- Agreement on things to work on until next visit

Session 6 Different ways of looking at numbers

- Blood glucose (BG) tests and your reasons for checking

- Actual BG numbers and wishes

- Your plan for BG regulation in the short and long run

- Common name for a difficulty in your life with diabetes

- Agreement on things to work on until next visit

Session 7 Problem identification and problem-solving

- Current problem-solving (parents)

- Dynamic problem-solving (parents)

- Solved problems and subjects to continue working on

The adolescents completed reflection worksheets at all sessions; it is noted in parentheses when the parents completed adapted worksheets.

CSII, continuous subcutaneous insulin infusion; GSD-Y, Guided Self-Determination-Young; HBA1c, hemoglobin A1c.

selected 13 adolescents (38\%) with type 1 diabetes (7 boys and 7 girls aged 12-20 years) from 37 adolescents who had participated in the intervention group, after they had completed their education sessions with GSD-Y at three hospitals located in central Sweden. ${ }^{11}$ When the participants were included in the RCT study, the median age (range) was 14.8 years (11.5-18), the median 
hemoglobin A1c (range) was $63 \mathrm{mmol} / \mathrm{mol}$ (57-101), and the median diabetes duration (range) was 4.5 years $(0.7-12.2)$. Of 14 who were asked to participate, one girl declined. The participants had no relationship with the researcher prior to the interview.

The adolescents received information verbally about the study when asked to participate. Written information about the study was also provided to, and consent obtained from, the participants for the interviews. For those under 15 years old, written consent was obtained from a parent. ${ }^{17}$

\section{Data collection}

An interview guide was designed according to the purpose of the study, including the following semistructured questions (probing questions were also used):

- About the group sessions (eg, What comes to mind when you think of the group sessions? What do you think was good about the sessions?).

- About the parents (eg, Can you tell me what it was like having your parents in the group? Can you tell me what things are like at home? Has anything changed?).

- About diabetes self-management (eg, Tell me what you think about having diabetes after having been involved in this program).

The interviews lasted 11-60 min. All interviews were recorded, and a secretary transcribed them verbatim.

\section{Data analysis}

The analysis was performed as follows:

Step 1: The transcribed interviews were read through several times to obtain a sense of the whole (ALB, JL). After 13 interviews, all authors agreed that saturation had been reached.

Step 2: The transcribed text was divided into units of meaning, which were condensed and labeled with codes (ALB, JL). The codes were then discussed in the research group (all authors).

Step 3: The various codes were compared. The research group looked for similarities and differences, and then sorted the codes into subcategories. Two main categories were revealed (by consensus among all authors). Two of the authors (ALB, JL) discussed and verified that the coding was congruent with the units of meaning.

Step 4: The categories were carefully assessed based on internal homogeneity (ie, data belonging to the same category were judged to be related in a meaningful way) and external heterogeneity (ie, the categories were distinguishable in that the differences among them were clear). ${ }^{15}$ The analysis was based on a manifest interpretation of the text. When all authors made a latent interpretation of the content, an overarching theme was revealed.

\section{RESULTS}

From the analysis, two categories were revealed-the importance of context and growing in power through the group process (figure 1). Meeting others in the same situation is important. It creates a sense of belonging and mitigates the feeling of loneliness. Sharing thoughts and experiences gives adolescents new ideas and tools for how to self-manage their diabetes in daily life. An overarching theme that emerged from the interviews was the importance of expert and referent power in growing awareness of the importance of self-management as well as mitigating the loneliness of diabetes.

\section{The importance of context}

\section{Participants}

The participants reported that meeting others with diabetes in their age group and situation was a positive and enjoyable experience. They experienced both advantages and disadvantages of the age distribution. Older adolescents expressed concern that the experience could be difficult as well as exciting and/or instructive for younger participants. Younger participants described experiencing no barriers for them between the different age groups:

...I could talk even though I was the youngest in the group. (Boy aged 12)

The older adolescents reported that they had learnt from the younger participants' accounts of their experiences. However, there were some who found it easier to relate to adolescents of the same age and who felt that too great an age gap hindered mutual dialogue:

... well...I'm 17, and I was sat there with a 13-year-old. And we couldn't really talk about the same things. (Boy aged 17)

The experience of being placed in mixed groups containing both boys and girls was perceived as positive:

Diabetes has no gender. (Girl aged 16)

\section{Location}

The adolescents found that having the sessions in the hospital was beneficial:

I think that if you're talking about your disease, you should be in the hospital. (Boy aged 15)

The groups were mixed and contained participants from all the clinics included in the study. Those who attended education sessions in a clinic they did not usually visit perceived this as a positive aspect of the program.

\section{Group leaders}

Participants emphasized the importance of the role of the group leader, and valued a positive and permissive atmosphere. It was seen as positive that the group leaders were not the same people they usually met at their diabetes clinics. Because of this, the leaders were perceived as neutral-people with whom they could reflect on their experiences, rather than someone whose job was to take care of them. As one girl expressed: 


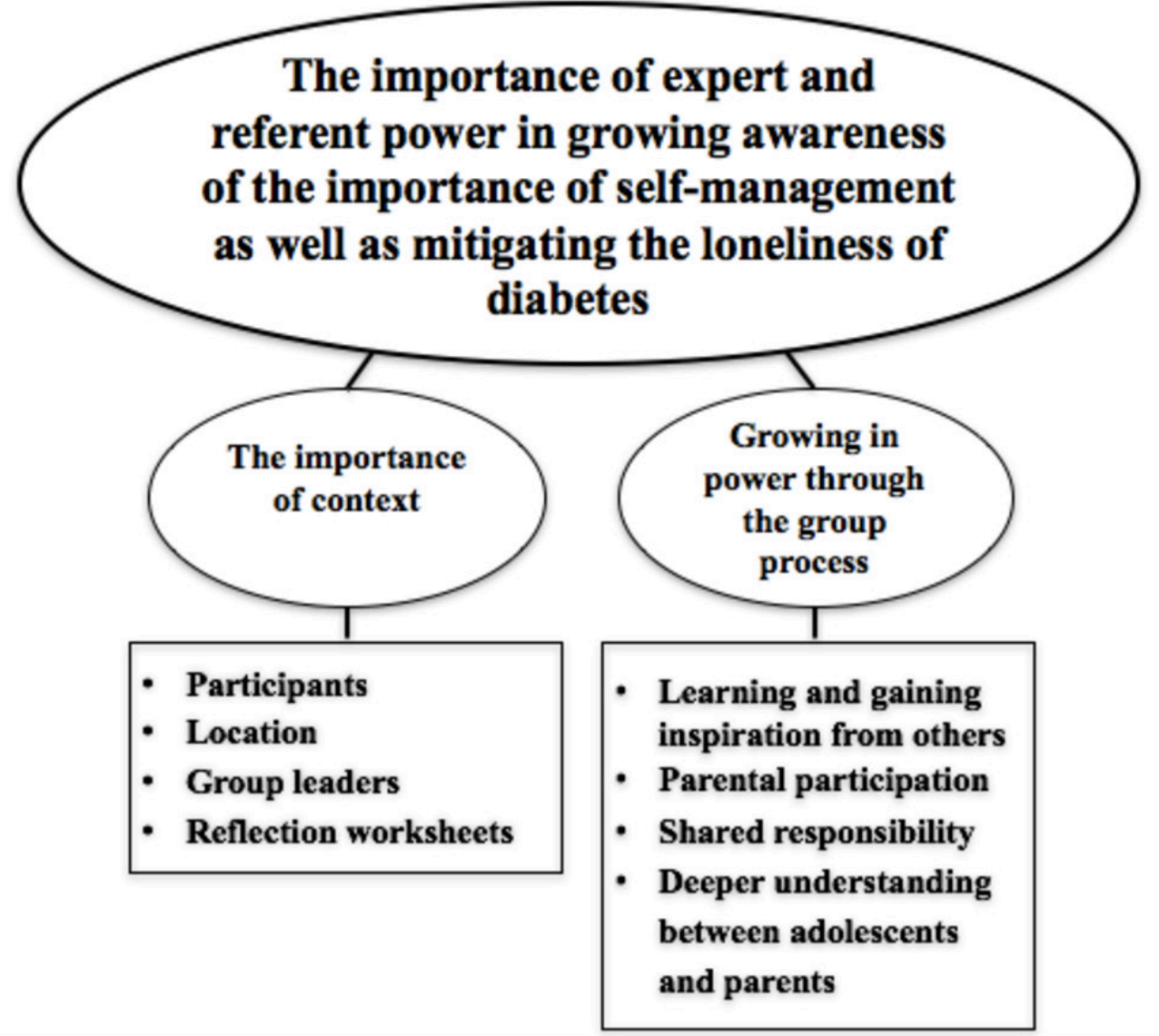

Figure 1 Description of the overarching theme, main categories, and subcategories emerging in the analysis.

They were more like people I could talk to instead of people who needed to take care of me...it was really nice in that respect. (Girl aged 16)

\section{Reflection worksheets}

Overall, participants reported that the reflection worksheets used in the conversations were useful because they resulted in deeper reflection and gave them the opportunity to express themselves in different ways. They helped them address issues they would not otherwise have discussed:

...you could write down anything you wanted there. Maybe there were a few things you avoided, but in the end they came up anyway...they came up naturally, in a better way, which felt good. (Boy aged 16)

Many of the younger participants needed help from their parents, both in completing the worksheets and during reflection work in the group. They perceived the reflection worksheets as too long, sometimes difficult to understand, and too time-consuming to fill in.

In one session, the aim of the worksheet was to visually describe the participants' images and thoughts regarding living with diabetes. The participants appreciated this and described it as fruitful. Furthermore, they expressed that the activity required creativity and made for a pleasurable learning experience, and was not seen as a hard task that had to be completed:
I think it's great to be able to visualize what you think and feel. It's one of the best things you can do besides writing and talking. (Girl aged 16)

When the participants expressed themselves visually, thoughts and feelings surfaced that would have been difficult to express in words:

I got to know my inner self and let my imagination go.

(Boy aged 16)

However, it should be noted that the session involving the visual expression of thoughts and feelings was not considered suitable for all participants.

\section{Growing in power through the group process Learning and gaining inspiration from others}

The importance of meeting other young people in the same situation and sharing experiences of living with diabetes was highlighted by most of the participants. These factors fostered a sense of belonging that could counteract the loneliness of living with diabetes.

...it was nice to find out that other people also have diabetes. I've also become a little more open to having diabetes. I've accepted it a little more, I think. (Boy aged 15)

Differences in diabetes self-management led to conversations that resulted in the sharing of ideas, knowledge, and advice among participants. Participants stated that it 
felt good to hear how others thought, and to understand that their differences were not always significant:

...you got to hear everyone's version of the perfect life and perspective on the question. (Boy aged 12)

Listening to others' stories, and sharing their own, was perceived as positive and encouraging. Participating in group conversations was perceived as worthwhile, inspiring, and encouraging by most of the participants. It was seen as useful and valuable to be able to share experiences with people in the same situation, on both a practical and a psychosocial level:

\begin{abstract}
It helps mentally. Perhaps even physically...if for example you become motivated to count carbohydrates or something like that. It was really motivating. And then you realize there are more people out there like you who have the same problems you have with taking care of diabetes... (Boy aged 16)
\end{abstract}

Some of the adolescents expressed having felt before the program that one's value as a human being was based on blood sugar levels, while after the intervention they no longer perceived blood sugar levels as a determinant of value:

They don't judge us based on our blood glucose values anymore. It's not 'you had 5.4 GOOD' or 'you had 14 BAD'. Now a value is a blood glucose value and nothing else. (Girl aged 17)

When sharing experiences and feelings about diabetes, several participants stated that they appreciated getting support from others who had similar experiences. Dialogues about various experiences and situations related to topics such as blood glucose, food, exercise, and treatment inspired participants to seek solutions to problematic situations in daily life:

For example, one of the people there played a lot of sports (ice hockey) and it had fallen off (his insulin pod, part of the Omnipod insulin pump), and he told us how he had fixed it. (Boy aged 15)

Several participants reported having learnt to make changes in their diabetes self-management and gained insight into the importance of taking care of themselves based on the group discussions:

Before, I wanted to show my doctor that I had good blood sugar, but now I'm motivated by much more than that. I want to feel well and have good blood sugar so I can do the things I enjoy. (Girl aged 17)

Among the older participants, some expressed a desire to be a role model:

I had to think of the others - that they also had to take blood sugar tests - I had to keep trying to pretend to be a good example for the whole group, somehow... it was positive, in some way. But there's quite a lot of responsibility that goes with it. (Girl aged 17)

Adolescents found the discussion very fruitful when the group was divided into two subgroups, one for adolescents and one for parents. Adolescents reported that this separation gave them the opportunity to reflect on subjects they did not wish to discuss in their parents' presence or on issues linked to their parents:

You're a small group of young people in a smaller room. You're closer to each other. It's easier to talk, and I remember that you could talk about more private things and stuff like that. (Boy aged 16)

\section{Parental participation}

The adolescents expressed that parental participation in diabetes self-management was important and worthwhile. They also believed it was beneficial for parents to share their experiences with other parents of children with diabetes:

...how they think about diabetes and the responsibilities they have and what they're afraid of, difficult things... from their perspective... because they don't have diabetes themselves. (Girl aged 16)

Several adolescents stated that they perceived their parents to be calmer and more relaxed after participating in this intervention, in comparison to their demeanor before the intervention. The importance of having conversations and sharing experiences with one's parents was also strongly emphasized:

...imagine having someone in your family who didn't support you or care that you have diabetes. That this is possible was a real eye-opener. (Girl aged 17)

\section{Shared responsibility}

After the intervention, the adolescents found that parental responsibility and support became more balanced and transparent. They felt that their parents trusted them more and felt more confident in their abilities, while the effect on the distribution of responsibilities varied; in some cases it increased or decreased, whereas in others it remained unchanged. Parental support was viewed as relevant based on the adolescent's responses. Parents are a source of security, advice, and support, and the adolescents expressed that they would feel alone without this support. A young person's need for support and cooperation with parents is of the utmost importance:

Before, they used to ask if I'd taken insulin today, if I'd taken a blood glucose test, but now they don't. Instead, I come home and put the insulin stuff in a cupboard, and then they just check and see if I've done it. (Boy aged 15) Cooperation within the family is important when you're young, to know that you can really get support from your parents. (Girl aged 20)

The adolescents had difficulty describing the ways their families distributed responsibility:

You don't need to divide the diabetes between you like you're doing that and you're doing that; rather, everyone has to do everything together. But I can say that my dad's been more like...yes, getting prescriptions filled 
and things like that, while Mum's the one I've talked to more...It's worked well like that, so in a way we have split it up a bit. (Girl aged 20)

\section{Deeper understanding between adolescents and parents}

The adolescents expressed that they had gained a better understanding of their parents' anxiety and behavior after having listened to their thoughts and experiences. They also described the benefits of listening to the experiences of other adolescents' parents:

They (the parents) are worried, maybe twice as much as regular parents, they don't only worry about their child being run over or something like that. (Girl 16 years)

Relationships and communication between adolescents and parents have changed, resulting in less nagging and conflicts:

...you could joke about what they did. No, I've never thought about how much they, say, test, check, and stuff like that. (Boy aged 12)

The adolescents experienced an improved level of understanding from their parents about how young people think about diabetes:

Mum and Dad might understand a bit more about diabetes after we've done this and understand how I feel about it...so it's a bit nicer at home. (Boy aged 15)

Some of the adolescents expressed that their diabetes self-management had previously been handled the way their parents wanted, which had led to conflicts. After participating in the education program, however, the adolescents' autonomy increased and this was supported by their parents:

I decide a bit more now. I'm the one who decides a bit more about the diabetes. After all, I'm the one who has it. (Boy aged 15)

One result that clearly emerged was that nagging takes on another dimension once you understand the reasons behind it. This understanding also resulted in experiences of fewer conflicts:

...they say, okay, maybe we've been nagging. But they always say it's because they care. ...well, now that I'm older, I realize it's just because they care, and not because they want to be mean or anything... (Girl aged 20)

\section{CONCLUSIONS}

Our analysis revealed one overall theme to describe adolescents' perceptions and experience of participation in a group-based GSD-Y education program. The theme is formulated as follows: the importance of expert and referent power in growing awareness of the importance of self-management as well as mitigating the loneliness of diabetes.

To interpret and understand the results, we have used theoretical frameworks based on Barrett ${ }^{18}$ and French and Raven (1959). ${ }^{18} 19$ Barrett defines power in healthcare as 'the capacity to participate knowingly in change', including four interrelated dimensions-awareness, choices, freedom to act intentionally, and involvement in creating change. ${ }^{18}$ Another dimension of the concept is social power as described by French and Raven (1959), who divide it into five forms. Two forms-referent and expert power-are relevant to the context of this paper. Referent power is defined as the ability of some individuals to serve as a reference for others. They can induce changes in the attitudes, values, and decisions of others. Expert power is knowledge resulting from experience or education. ${ }^{19} 20$

The adolescents highlighted the need to meet others in the same situation as themselves and to share experiences, which is well known from previous studies involving both adolescents and adults. ${ }^{21}{ }^{22}$ Participants in the current study emphasized that meeting others creates space for reflection and conversation about both concrete everyday issues, such as feelings and thoughts, and taking responsibility for diabetes self-management. In our analysis, based on the theoretical framework, it became clear that the named factors are of importance for increasing the referent power. A prerequisite for creating space regarding referent power in a group is the group leaders' competence and approach, that is, expert power. This is in line with the GSD-Y method, which highlighted the group leaders' role in guiding the participants to reflect in a way that would lead to decisions. ${ }^{9}$

The adolescents appreciated the reflection worksheets and found them to be a valuable tool in conversations. The reflection worksheets highlighted things that otherwise would not have been mentioned and helped in a structured way to deepen the dialogue, leading to clarifications about current and real problems experienced when living with diabetes. These results confirm that the reflection worksheets are tools that help overcome barriers, as described in previous research. ${ }^{10} 23$

The analysis revealed an additional success factor of GSD-Y, when participants were asked to describe through words or images how they imagine a life with diabetes (table 1, session 4). Visually describing images and thoughts was experienced as liberating and creative for several of the adolescents. In this context, it was a new, positive way to prepare reflections. They felt it was undemanding and led to new ideas. These results are consistent with the study by Piana $e t a l^{4}$ which described how adolescents describing their diabetes in words as stressful, but at the same time found that visually describing their thoughts was liberating and that their self-image and relationships with others and the disease benefitted from it. Buber and Smith argue that humans want to create, and that it is a natural way to 'learn'. Visually expressing themselves, without expectations, creates a natural way for humans to express themselves and, as a result of this, allows them to reflect and learn. ${ }^{25}$ 
A feeling of loneliness was a common factor among participants that emerged in our study, as were difficulties in handling diabetes self-management in everyday life.

In the analysis, according to referent power and Barrett's theory, we interpret that reflections and dialoguesincluding giving advice to each other, creating an arena for making choices about what changes they wanted to perform in daily diabetes self-management. ${ }^{18}$ In general, the analysis showed that the named factors were of importance in mitigating loneliness and an increased awareness of self-management.

Parents were considered to have become more aware of the adolescents' viewpoints and experiences, and the adolescents perceived positive changes in their parents' demeanor after participating in GSD-Y. Previous research has shown that parents are worried about their adolescents' future and the possibility of developing complications. ${ }^{26}$ The adolescents appreciated parental participation and found it valuable, which led to an increase in their mutual respect for and understanding of each other, as well as improved communication, resulting in a modified distribution of responsibilities, which reduced nagging and conflicts. Adolescents withmore conflicts take fewer blood glucose tests and have poorer blood glucose control..$^{27}$ Constructive communication between parents and adolescents seems to be an important component of diabetes self-management. ${ }^{4} 28$ This emphasizes the importance of parental involvement and constructive parental support. ${ }^{242829}$ As a contrast, a study of a group education program that did not involve parents had no effect on glycemic control or empowerment outcomes. ${ }^{30}$

GSD-Y has, in different ways, mitigated experiences of loneliness and contributed to conscious reflection regarding self-management in the group (referent power) together with the group leader (expert power). Overall, this highlights the benefits of group education, and the GSD method emphasizes the person-centered approach.

\section{Study limitation}

As we wanted to explore whether there was a pattern in adolescents' experiences of participation in the intervention, we chose qualitative content analysis for this study. ${ }^{15} 31$ One of the highlighted advantages of qualitative content analysis is that it is sensitive to the content and flexible in design, and it is an established method. ${ }^{32}$

We have strived to achieve trustworthiness (credibility, dependability, confirmability, and transferability) by describing the analytical process in detail, providing quotations from the interviews, involving several researchers in the analyses, and describing the sample and context in as much detail as possible. ${ }^{15} 31$ Since the study was small-scale, the potential transferability of the findings may be limited. However, previous research using the GSD method has shown promising results. ${ }^{1023}$
The majority of interviews were conducted in close proximity to the intervention-within a few months-but one participant was interviewed after a year. This could be a weakness, but none of the researchers involved in the analyses noted any major differences. The different intervals between intervention and interviews may have increased the trustworthiness; the results were consistent despite the varying intervals. Further, the parents were not interviewed; if they had been, this might have increased the trustworthiness of the results.

When participants were selected, we used purposeful sampling with maximum variation. The interviewed adolescents were fairly equally distributed between boys and girls, and there was variation in age.

A weakness is that participants' demographic data were not collected; this could have been interesting to add to the results. Another limitation of the study was that the participants were aware of the researchers' involvement in the intervention, which may have affected the results.

Two researchers conducted the first three interviews. They got the impression that this did not affect the adolescents, but having two adults present might have hindered the adolescents in expressing their perspectives. None of the researchers who conducted the interviews had a close relationship with the adolescents.

\section{Implications for future research}

From the participants' point of view, education in groups with GSD-Y was appreciated as an important tool to help overcome barriers in daily life with diabetes and communication with parents. An advantage of GSD-Y compared with other methods is the worksheets, which support reflection regarding significant issues involving diabetes. However, the worksheets need to be revised and tested in a clinical context. Further studies are needed to investigate factors contributing to loneliness in adolescents living with diabetes and to explore whether young people with type 1 diabetes feel more lonely than young people without diabetes.

Acknowledgements We would like to thank the adolescents who shared their thoughts and experiences. We would furthermore like to thank Elisabeth Jelleryd (dietitian) at Karolinska University Hospital Huddinge, Monica Bruns Håkansson (RN) at Södersjukhuset, Stockholm and Margaretha Blom (RN) at Södersjukhuset, Stockholm, who were involved in the GSD-Y conversations.

Contributors ALB contributed to the study design, conducted data collection, analysed and interpreted data, and wrote the manuscript. ALO contributed to the study design, analysed and interpreted data, and reviewed/edited the manuscript. GV contributed to the study design, analysed and interpreted data, and reviewed the manuscript. TG reviewed and edited the manuscript, and contributed to the discussion. JL contributed to the study design, conducted data collection, analysed and interpreted data, and reviewed the manuscript.

Funding This study was supported by grants from Barndiabetesfonden (the Swedish Child Diabetes Foundation), Diabetesförbundet (the Swedish Diabetes Association Research Foundation), funding for care research from Uppsala University, Diabetesstiftelsen (the Swedish Diabetes Foundation), the Sven Jerring Foundation, the Clas Groschinsky Memorial Fund, and Swedish Association for Nurses in Diabetes Care (SFSD).

Competing interests None declared.

Patient consent Parental/guardian consent obtained. 
Ethics approval The Ethical Review Board in Stockholm, Sweden, approved the study (2011/762-31/4 and 2012/2124-32), which was carried out in accordance with the Declaration of Helsinki.

Provenance and peer review Not commissioned; externally peer reviewed.

Open Access This is an Open Access article distributed in accordance with the Creative Commons Attribution Non Commercial (CC BY-NC 4.0) license, which permits others to distribute, remix, adapt, build upon this work non-commercially, and license their derivative works on different terms, provided the original work is properly cited and the use is non-commercial. See: http://creativecommons.org/ licenses/by-nc/4.0/

(c) Article author(s) (or their employer(s) unless otherwise stated in the text of the article) 2017. All rights reserved. No commercial use is permitted unless otherwise expressly granted.

\section{REFERENCES}

1. Silverstein J, Klingensmith G, Copeland K, et al.Care of children and adolescents with type 1 diabetes: a statement of the American diabetes association. Diabetes Care 2005;28:186-212.

2. Olinder AL, Nyhlin KT, Smide B. Clarifying responsibility for selfmanagement of diabetes in adolescents using insulin pumps--a qualitative study. J Adv Nurs 2011;67:1547-57.

3. Cameron FJ, Amin R, de Beaufort C, et al.ISPAD clinical practice consensus guidelines 2014. Diabetes in adolescence. Pediatr Diabetes 2014:15 Suppl 20:-245-56.

4. Viklund G, Wikblad K. Teenagers' perceptions of factors affecting decision-making competence in the management of type 1 diabetes. $J$ Clin Nurs 2009;18:3262-70.

5. World Health Organisation-WHO. Health for the world's adolescents - a second chance in the second decade. 2014 http://apps.who.int/ adolescent/second-decade/.

6. Scholes C, Mandleco B, Roper S, et al. A qualitative study of young people's perspectives of living with type 1 diabetes: do perceptions vary by levels of metabolic control? J Adv Nurs 2013;69:1235-47.

7. Lange K, Swift P, Pańkowska E, et al.ISPAD clinical practice consensus guidelines 2014. Diabetes education in children and adolescents. Pediatr Diabetes 2014;15 Suppl 20:77-85.

8. Zoffmann V, Kirkevold M. Life versus disease in difficult diabetes care: conflicting perspectives disempower patients and professionals in problem solving. Qual Health Res 2005;15:750-65.

9. Zoffmann V, Harder I, Kirkevold M. A person-centered communication and reflection model: sharing decision-making in chronic care. Qual Health Res 2008;18:670-85.

10. Husted GR, Esbensen BA, Hommel E, et al. Adolescents developing life skills for managing type 1 diabetes: a qualitative, realistic evaluation of a guided self-determination-youth intervention. $J$ Adv Nurs 2014:70:2634-50.

11. Brorsson AL, Leksell J, Viklund G, et al. A multicentre randomized controlled trial of an empowerment-inspired intervention for adolescents starting continuous subcutaneous insulin infusion--a study protocol. BMC Pediatr 2013;13:212.
12. Cai RA, Holt RIG, Casdagli L, et al. Development of an acceptable and feasible self-management group for children, young people and families living with Type 1 diabetes. Diabet Med 2017;34:813-20.

13. Sawtell M, Jamieson L, Wiggins $M$, et al. Implementing a structured education program for children with diabetes: lessons learnt from an integrated process evaluation. BMJ Open Diabetes Res Care 2015;3.

14. Krippendorff K. Content analysis: an introduction to its methodology. 3rd ed. Los Angeles: London: SAGE, 2013.

15. Patton MQ. Qualitative research \& evaluation methods. 4th ed. London: SAGE, 2014.

16. Kvale S, Brinkmann S. InterViews: learning the craft of qualitative research interviewing. 2nd ed. London: Thousand Oaks:Sage Publications, 2009.

17. CODEX: rules and guidelines for research (Council of science) uppsala: vetenskapsrådet. 2017 http://codex.vr.se/.

18. Barrett EA. Power as knowing participation in change: what's new and what's next. Nurs Sci Q 2010;23:47-54.

19. Buchmann WF. Adherence: a matter of self-efficacy and power. J Adv Nurs 1997;26:132-7.

20. Rodin J, Janis IL. The social power of health-care practitioners as agents of change. J Soc Issues 1979;35:60-81.

21. Carroll AE, Marrero DG, Swenson MM. Why do adolescents with type 1 diabetes and their parents participate in focus groups? Res Theory Nurs Pract 2007;21:135-42.

22. Mendenhall TJ, Seal KL, Greencrow BA, et al. The family education diabetes series: improving health in an urban-dwelling American Indian community. Qual Health Res 2012;22:1524-34.

23. Zoffmann V, Kirkevold M. Realizing empowerment in difficult diabetes care: a guided self-determination intervention. Qual Health Res 2012;22:103-18.

24. Piana N, Maldonato A, Bloise D, et al. The narrative-autobiographical approach in the group education of adolescents with diabetes: a qualitative research on its effects. Patient Educ Couns 2010;80:56-63.

25. Buber M, Smith RG. Between man and man. London: Routledge, 2002.

26. Hendrieckx C. Abstracts for the 42nd annual meeting of the International Society for Pediatric and Adolescent Diabetes (ISPAD) Valencia, Spain (INV 12). Pediatr Diabetes 2016;17(Suppl 24):5-176.

27. Ingerski LM, Anderson BJ, Dolan LM, et al. Blood glucose monitoring and glycemic control in adolescence: contribution of diabetes-specific responsibility and family conflict. J Adolesc Health 2010;47:191-7.

28. Herbert LJ, Sweenie R, Kelly KP, et al. Using qualitative methods to evaluate a family behavioral intervention for type 1 diabetes. $J$ Pediatr Health Care 2014;28:376-85.

29. Karlsson A, Arman M, Wikblad K. Teenagers with type 1 diabetes--a phenomenological study of the transition towards autonomy in selfmanagement. Int J Nurs Stud 2008;45:562-70.

30. Viklund G, Ortqvist E, Wikblad K. Assessment of an empowerment education programme. A randomized study in teenagers with diabetes. Diabet Med 2007;24:550-6.

31. Polit DF, Beck CT. Nursing research: generating and assessing evidence for nursing practice. xviii. 8 ed. Philadelphia: Wolters kluwer Health and Lippincott Williams \& Wilkins, 2008:796.

32. Elo S, Kyngäs $\mathrm{H}$. The qualitative content analysis process. J Adv Nurs 2008;62:107-15. 